\title{
Análise de resistência à compressão e à flexão de perfil de seção tubular formado a frio com diferentes geometrias
}

Marcio Vito ${ }^{3}$

\section{Introdução}

Os perfis de aço formados a frio (PFF) são cada vez mais viáveis para uso na construção civil, em vista da rapidez e da economia exigidas pelo mercado. Esse elemento estrutural pode ser eficientemente utilizado em galpões de pequeno e de médio porte, coberturas, mezaninos, em casas populares e edifícios de pequeno porte (SILVA; PIERIN; SILVA, 2014). Uma vantagem que os PFF possuem em relação ao aço laminado é a grande variedade de formas e seções transversais que podem ser obtidas, por se tratar de um processo industrial menos oneroso, facilitando a otimização de sua geometria em relação a seu carregamento. Ainda como vantagem, a obtenção de perfis rígidos a partir de chapas finas traz boa relação massa por resistência. Esse fato fez o PFF alcançar lugar de destaque nas estruturas de aço (NANDHAKUMAR; RAMESH; SREEVIDYA, 2019). A presente pesquisa focou em analisar e comparar a resistência mecânica de um perfil de aço tubular circular convencional (modelo encontrado no comércio) dobrado em mesa de roletes e um perfil de aço tubular circular formado em prensa dobradeira, com as execuções de doze e seis dobras. Foram avaliadas a resistência à compressão e a resistência à flexão dos elementos citados por ensaio de compressão direta e flexão estática a quatro pontos.

\section{Metodologia}

O aço empregado na obtenção dos tubos analisados foi o SAE 1010, por ser um material comum na fabricação de tubos industriais e atender à solicitação de relação entre limite

\footnotetext{
${ }^{1}$ Acadêmico de Engenharia Civil, Universidade do Extremo Sul Catarinense, daniel_sehnem@hotmail.com

${ }^{2}$ Mestre, Engenheiro Civil, Universidade do Extremo Sul Catarinense, augustoawd@gmail.com

${ }^{3}$ Mestre, Engenheiro Civil, Universidade do Extremo Sul Catarinense, marciovito@unesc.net
} 
de resistência à tração e à tensão de escoamento exigida pela norma NBR 14762:2010. Essa escolha também levou em consideração a NBR 6591:2008. Os perfis dobrados em prensa dobradeira foram fabricados em duas partes com iguais dimensões e ligados longitudinalmente por duas linhas de solda de topo, conforme AWS A5.1, em todo o seu comprimento. 0 ensaio de flexão estático a quatro pontos foi realizado nos tubos com $2500 \mathrm{~mm}$ de comprimento. No ensaio de compressão direta, o comprimento adotado foi de $450 \mathrm{~mm}$. Essas dimensões fornecem uma escala real de utilização dos tubos e evitam a ocorrência de flambagens laterais ou por flexão. A Figura 1a mostra a montagem do ensaio de compressão direta em um dos tubos, e a Figura $1 b$ é relativa ao ensaio de flexão. Os equipamentos utilizados na realização dos ensaios foram o macaco hidráulico e a célula de carga da marca HBM para a aplicação e a obtenção do carregamento, sendo este aplicado de forma monotônica a fim de simular uma carga estática. No ensaio de flexão para aferir os deslocamentos verticais foram acoplados ao tubo no centro do vão dois medidores LVDT (Linear Variable Differential Transformer). Essas informações foram transmitidas para um computador por meio do sistema de dados QuantumX MX840B da marca HBM. Os ensaios foram realizados no Laboratório Experimental de Estruturas do Parque Científico e Tecnológico (Iparque) da UNESC.
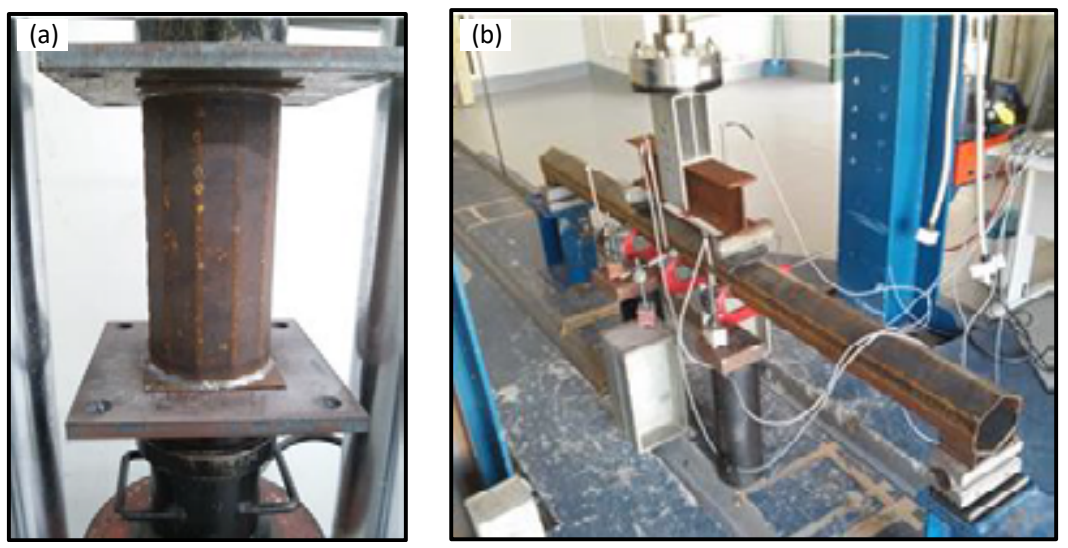

Figura 1 - (a) amostra montada no ensaio de compressão direta e (b) amostra montada para o ensaio de flexão estática a quatro pontos.

Fonte: Acervo dos autores.

\section{Resultados}

Os tubos apresentaram pequena variação entre as peças de mesma forma geométrica, mas o comportamento diferiu quando comparada uma geometria com outra. 
Todas as amostras foram levadas até a ruptura, porém a NBR 8800: 2008 estabelece limites de deslocamentos máximos, conforme a utilização do elemento, onde ele será aplicado, e a carga de ruptura extrapolou os limites máximos de deslocamento. Durante a execução dos ensaios, foi estabelecido o deslocamento máximo de $70 \mathrm{~mm}$. Esse valor foi escolhido, pois em todas as amostras já se observava a redução de carga. Para os gráficos comparativos entre as diferentes formas geométricas, utilizou-se uma média dos resultados das três amostras de cada tipo de seção. Essa análise consta graficamente nas Figura 2 e 3. Para os ensaios de flexão, o perfil circular apresentou resistência 13\% maior que o perfil dodecagonal e $15 \%$ maior que o perfil hexagonal. Para os ensaios de compressão, o perfil circular apresentou resistência $12 \%$ maior que o perfil dodecagonal e $22 \%$ maior que o perfil hexagonal. Percebeu-se que a variação de resistência à compressão apresentou diferença mais elevada em relação à resistência à flexão, mas proporcionalmente similar, uma vez que a resistência à compressão é maior que a resistência à flexão nesse ensaio. A conformação do material à temperatura ambiente modificou as regiões dobradas de elásticas em plástica, apresentando maior resistência mecânica nas regiões em que o material foi conformado por meio do fenômeno de encruamento, conforme NBR 14762 (2010), porém essa norma também indica que os perfis tubulares com seção transversal circular devem ser dimensionados seguindo a NBR 8800, a qual não considera o aumento de resistência devido à dobra e analisa o material como aço virgem, uma vez que o perfil tubular pode ser fabricado também por extrusão.

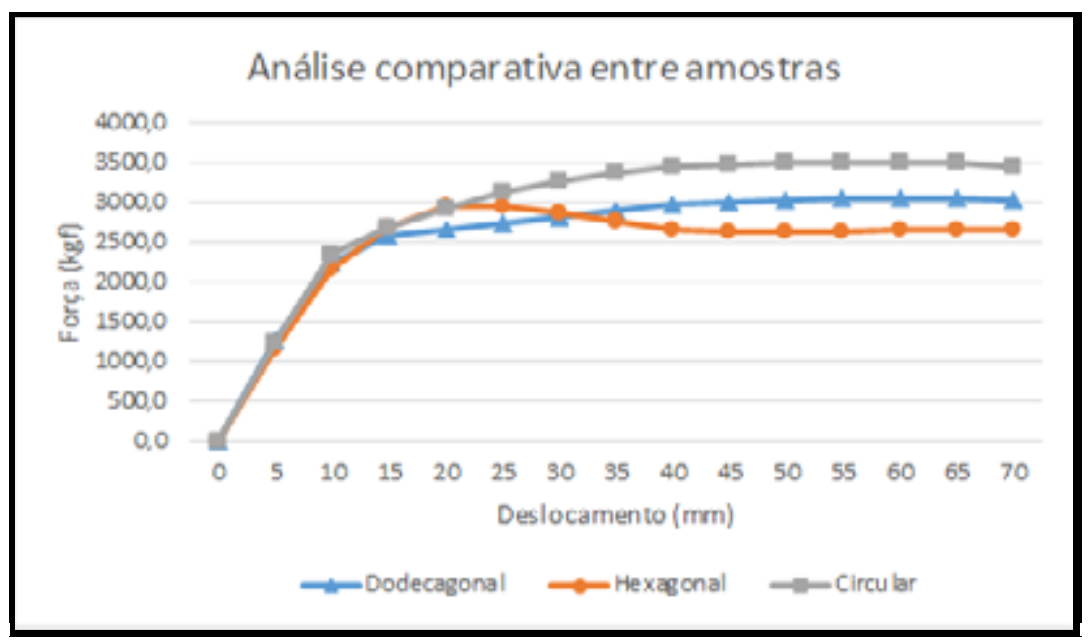

Figura 2 - Média dos resultados do ensaio de flexão estática em carga por deslocamento vertical.

Fonte: Elaborada pelos autores. 


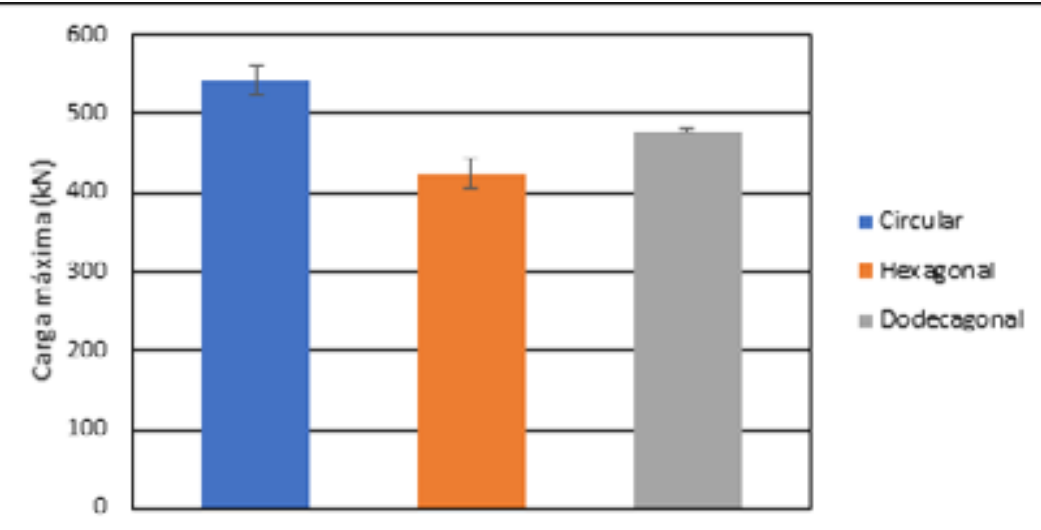

Figura 3 - Resultados médios com desvio padrão representado nas barras de erro para o ensaio de compressão direta.

Fonte: Elaborada pelos autores.

\section{Conclusões}

A viabilidade da substituição dos tubos com diferentes processos de fabricação pôde ser realizada satisfatoriamente nos quesitos de resistência mecânica. Essa substituição trouxe vantagens, já que um perfil formado a frio não ficou limitado às dimensões predeterminadas, podendo otimizá-lo para a obtenção da redução de custos de mão de obra e do uso de material. Também é possível afirmar que a quantidade de dobra tem relação com o aumento da resistência do perfil. O perfil hexagonal teve seis regiões plastificadas e apresentou resultado médio menor que o perfil dodecagonal, o qual teve doze regiões plastificadas. Já o perfil circular se apresentou o mais resistente, justamente porque a plastificação do processo de fabricação em mesa de roletes não ocorreu apenas em pontos do perfil, mas se estendeu ao longo de todo o perímetro, plastificando toda a seção transversal do perfil.

Palavras-chave: Perfil de aço tubular; Resistência à compressão; Resistência à flexão.

\section{Referênncias}

ASSOCIAÇÃO BRASILEIRA DE NORMAS TÉCNICAS (ABNT). NBR 14762. Dimensionamento de estruturas de aço constituídas por perfis formados a frio. Rio de Janeiro: ABNT, 2010. 87 p. 
ASSOCIAÇÃO BRASILEIRA DE NORMAS TÉCNICAS (ABNT). NBR 6591. Tubos de aço-carbono com solda longitudinal de seção circular, quadrada, retangular e especial para fins industriais - Especificação. Rio de Janeiro: ABNT, 2008. 10 p.

ASSOCIAÇÃO BRASILEIRA DE NORMAS TÉCNICAS (ABNT). NBR $\mathbf{8 8 0 0 . ~ P r o j e t o ~ d e ~}$ estruturas de aço e de estruturas mistas de aço e concreto de edifícios. Rio de Janeiro: ABNT, 2008. $237 \mathrm{p}$.

NANDHAKUMAR, C. S.; RAMESH, R.; SREEVIDYA, V. Investigation of cold formed steel beam subjected to torsion. Materials Today: Proceedings, jul. 2019.

PFEIL, W.; PFEIL, M. Estruturas de aço: dimensionamento prático. 8. ed. Rio de Janeiro: LTC, 2010. $357 \mathrm{p}$.

SILVA, E. L.; PIERIN, I.; SILVA, V. P. Estruturas compostas por perfil formado a frio. Rio de Janeiro: IAB, 2014. 193 p. 